\title{
CONTENT VALIDITY OF THE QUESTIONNAIRES
}

Title of the research: Effect of cooking fuels use on increased maternal carotid intima media thickness and preeclampsia among self-cooking pregnant women in Nay Pyi Taw Area, Myanmar: A cohort study

Researcher: Myo Min, MBBS, MMedSc (Disease Prevention \& Control), MIPH

Doctorate student, Public Health Program, College of Public Health Sciences, Chulalongkorn University

Objective: To investigate associations between type of cooking fuels use and increased maternal carotid intima media thickness (CIMT) and preeclampsia among self-cooking pregnant women in Nay Pyi Taw area, Myanmar

Semi-structured interviewer administered questionnaire form is composed of (15) items for sociodemographic factors, residential factors and cooking fuels use factors. The Item-Objective Congruence Index (IOC) was analyzed for questionnaires' content validity testing by the following experts:

\section{(1) Expert 1}

Dr. Kyae Mhon Htwe (M.B.,B.S; M.Med.Sc (Biochemistry), MPH)

Deputy Director/Head, Quality Assurance Division, Department of Medical Research

Email: kyaehmon.htwe.dr@gmail.com

$\mathrm{Ph}:+9591-375457$ ext: 501

\section{(2) Expert 2}

Dr. Tun Lin Maung (M.B.,B.S; M.Med.Sc (Obstetrics \& Gynecology)

Specialist, Zabuthiri Specialist Hospital, Nay Pyi Taw

Email: drmgtunlinmg@gmail.com

Ph: +9595121936

\section{(3) Expert 3}

Saowanee Norkaew, PhD

Faculty of Public Health, Thammasat University (Rungsit Campus)

The IOC index of the questionnaires was 0.92 .

According to the three experts, the content validity in terms of IOC index 0.92 is approved, and the questionnaires are to be used for data collection for objectives mentioned above. 